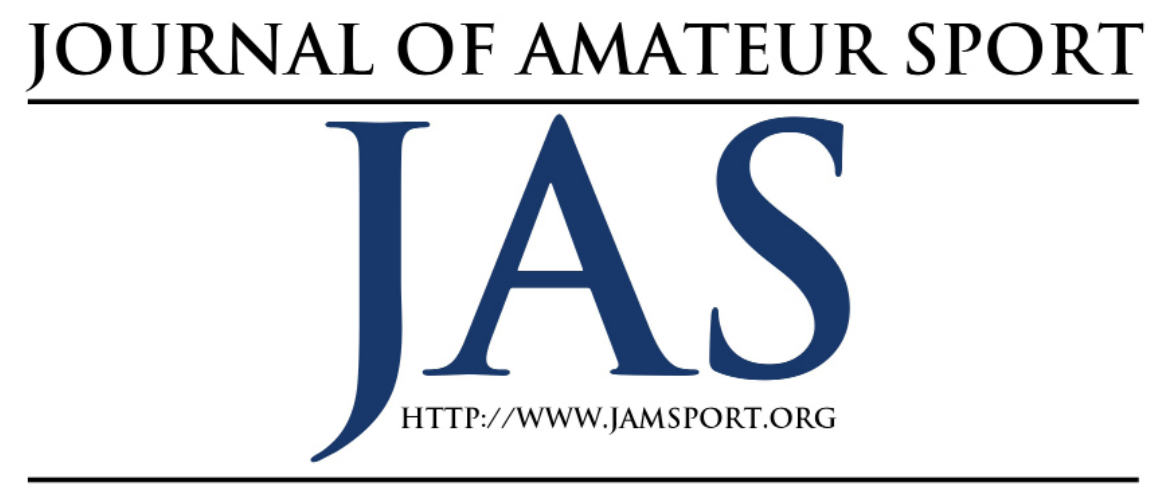

\title{
United States Soccer Referees' Preferences for Continuing Education
}

\author{
Vince Apple-Chiarella ${ }^{1} \quad$ Leilani Madrigal ${ }^{2}$ \\ Tiffanye M. Vargas $^{2}$
}

\author{
${ }^{1} A S F C$ \\ ${ }^{2}$ CSU Long Beach
}

\begin{abstract}
The purpose of this study was to assess the continuing education preferences of soccer referees registered with the United States Soccer Federation. Participants completed a Likert-type survey consisting of 18 topics asking them to rank how helpful they would consider each topic for continuing education. Results indicated that referees considered player management, using personality to manage games, and the decision-making process as the most important topics for continuing education. Administrative duties and handling were considered the least important topics. Less experienced referees wanted more administrative duty and player management topics than their more experienced peers. These findings suggest that referee curriculum should be reviewed and revised according to referee preferences.
\end{abstract}

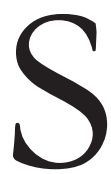

occer, as it is called in the United States, is the most popular sport worldwide (Dvorak, Graf-Baumann, Peterson, \& Junge, 2016). According to Palacios-Huerta (2004), hundreds of millions of youth around the globe practice soccer, with many more adults following it. Soccer competition requires three groups of people in order to op- erate properly and efficiently: athletes, coaches, and referees. Players are generally regarded as the most important of the three. Coaches are often a close second, considering that in certain leagues games cannot take place without a coach present, and the obvious benefits of coaches have been recorded through numerous studies (Cote, Young, North, \& Duffy, 
2007; Day, 2008; Leedham, 2005). Referee importance is highlighted by the International Football Association Board (IFAB). They, in conjunction with the Federation of International Football Associations (FIFA), write and update the 17 Laws of the Game that govern soccer worldwide. Of those 17 laws, two directly refer to match officials: Law 5, The Referee; and Law 6, The Assistant Referees.

Soccer officials face as much pressure and emotion-sometimes morethan the athletes and coaches (Zarrabi-Kashani, 2013). They are required to keep up with the speed of play for the duration of the match, while also recognizing and reacting to tactics being employed by both teams. They are expected to manage the many personalities that are present on the field at a given time and keep order in (sometimes hostile) environments; occasionally, while being berated by fans, players, coaches, or parents. To date, literature on referees have focused on issues such as stress responses (Dorsch \& Paskevich, 2007), use of coping (Wolfson \& Neave, 2007), motivation (Gray \& Wilson, 2008), and passion and decision-making (Philippe, Vallerand, Andrianarisoa, \& Brunel, 2009). While these have been beneficial to get a better understanding of this understudied population, they do not address the foundation of refereeing: referee training.

The United States Soccer Federation Referee Program (USSF) has nearly 140,000 registered referees throughout its 55 state associations (California, Texas, New York, Pennsylvania, and Ohio are broken into two state associations) ("ussoccer.com," 2017). The referee program has nine grades to categorize its referees; those grades are numbered from 1-16. Grades 13, 14, 15, and 16 are designated as emeritus grades and grant referees in those categories to continue officiating while no longer having to fulfill fitness and testing requirements. Referees will either start at the grade 9 (i.e., recreational youth referee), or grade 8 (i.e., competitive youth referee level), and progress their way down the grades, if they so choose. Currently, there are different educational requirements for each grade; however; modality and preference for such educational components has not been closely examined, which may have an influence on receptiveness and retention of important referee information.

U.S. Soccer has educational presentations that correspond to grade levels nine, eight, seven, and six. The grade nine and grade eight presentations include slides that provide an introduction to, and an overview of, each of the 17 laws of the game. No advanced topics are covered. The grade seven (i.e., amateur adult referee), presentation includes ideas that are more complex, and the grade six (i.e., state referee), presentation covers even more abstract ideas relevant to refereeing. U.S. Soccer does not currently have a presentation available for grade five (i.e., state referee), education.

Those officials with the grade four (i.e., national assistant referee), or grade three (i.e., national referee), distinction will attend National Camp to complete technical requirements which include passing the fitness test and attending classroom sessions. Upon completion of National Camp, officials are registered (ussoccer.com, 2017). These camps are planned and taught directly by U.S. Soccer Federation Referee program staff 
members, with special guest speakers approved by U.S. Soccer. These National Camps are held to ensure that national referees and national assistant referees are consistent in their understanding and interpretations of the Laws of the Game, and to ensure that each referee meets the minimum fitness and written testing standards.

The presentations for grade nine and eight referees contain information strictly pertaining to the Laws of the Game, with some abstract concepts (i.e., management, reading play, assistant referees, team work, extra persons, dissent, mass confrontation, foul recognition, advantage, contact above the shoulder, and report writing) being introduced in grade seven ("ussoccer.com," 2017). Grade six referees are presented with further nuance in the form of: 100\% misconduct, command presence, game management, kicks from the mark, managing the technical area, mentoring, professionalism, self-evaluation, simulation, the fourth official, qualities of top referees, and tactical awareness ("ussoccer.com," 2017).

As the popularity of youth sport rises, the availability of willing referees has declined (Theisen, 2017). Ridinger, Warner, Tingle and Kim (2017) agree as they note that more, and better quality, referees are needed. In a qualitative study, Jordan, Upright, and Forsythe (2019) used a convenience sample to interview 14 referees and learned the training could assist with recruitment. The findings also underscored the need to identify referee stressors and reasons for referee attrition as that could help develop improved referee training. This is consistent with Warner, Tingle and Kellett (2013), who interviewed 15 referees from across the
United States and learned that participants felt that proper training and mentoring would have aided in lessening the psychological stressors present. Thus, not surprisingly, these same referees also noted that the training that consisted of the wrong information contributed to referee attrition. Specifically, they noted that training which focused solely on knowledge of rules and rule enforcement, rather than teaching them how to deal with the bigger issues they would face, was potentially the biggest impact on whether or not to leave the profession.

There are several other key educational topics that have been noted as missing from current referee training. Referees need better knowledge of how to manage situations and promote perceptions of fairness (Cunningham, Simmons, \& Mascarehas, 2018), improve their communication skills (Fruchart \& Carton, 2012; Mellick, Bull, Laugharne, \& Fleming, 2005; Simmons, 2011) and how to work with the athletes (Cunningham, Simmons, \& Mascarehas, 2018; Nikbakhsh, Alam, \& Monzami, 2013). A study of 18 elite level soccer referees found that improved training resulted in improved ability to handle stressful situations, which in turn, helped the referee remain fair and unbiased. For these referees, the improved training included a 'referee coach,' or mentor, who worked with them to review videotaped performances to promote improvement (Webb, Dicks, Thelwell \& Nevill, 2018). The concept of providing mentorship (e.g., matching a professional level umpire with that of a novice) has been noted as an important component that is missing in current referee training (Kellet \& Warner, 2011; Ridinger et al., 2017). Such 
relationships could foster a greater sense of community, which may also help with attrition rates (Nordstrom, Warner, \& Barnes, 2016). Clearly, studies done largely qualitatively, have indicated there are many areas needed to improve referee education and training.

These studies highlight the importance of referee training. However, while many of these studies have been qualitative in nature and noted the importance of training, to the best of our knowledge, no research has tried to garner a large quantitative measure of the topics referees deem most important for continuing education. Additionally, because this research on the education needs of referees is a relatively new area, it becomes important to explore whether or not the amount of experience a referee has impacts his/her continuing education needs. Previous research has suggested that the experience level of the referee is a variable that should be controlled (Goldsmith \& Williams, 1992). Therefore, the purpose of this exploratory study is to determine: (1) soccer referees' preferences for continuing education, and (2) differences in continuing education preferences between experience levels.

\section{Participants}

The participants comprised 1,025 United States Soccer Federation referees ( $N=857$ males, $N=159$ females, while 9 didn't indicate a gender). Their ages ranged from 18 to $87(M=32.67, S D$ $=14.23$ ). Referees years of experience ranged from 0 to 50 years $(M=10.06$, $S D=7.53)$. The current referee grade of participants ranged from 3 to 16 , with 29 not indicating a current grade. More specifically, grade $3(N=1, .1 \%)$, grade 4 $(N=57,5.6 \%)$, grade $5(N=21,2.0 \%)$, grade $6(N=292,28.5 \%)$, grade $7(N=$ $374,36.5 \%)$, grade $8(N=188,18.3 \%)$, grade $9(N=2, .2 \%)$, grade $13(N=10$, $1.0 \%)$, grade $14(N=3, .3 \%)$, grade 15 $(N=29,2.8 \%)$, and grade $16(N=19$, 1.9\%). The referees represented 52 of the 55 state associations.

\section{Procedure}

Following Institution Review Board approval, participants were recruited at 10 tournaments, clinics, and camps organized by US Soccer or affiliated organizations. The events attended were chosen as they provided the opportunity to recruit referees from different regions, of varying experience levels, and genders.

Questionnaires and consent forms were distributed to referees and a short presentation was given explaining the purpose of the study. Depending on the setting, this occurred either at a table during registration or in large groups during meetings. The participants were assured that participation was optional and they were provided an overview of, and instructions for, the informed consent and questionnaire. Referees completed the questionnaire in three to fifteen minutes. Upon completion of the questionnaire confidentiality and anonymity was guaranteed by providing two different boxes for the referees, one to place the informed consent and one to place the questionnaire itself.

\section{Instrumentation}

Soccer Referee Continuing Education Survey (SRCES). To develop this questionnaire, 30 referees were asked to name a topic they would consider useful for continu- 
ing education; this question developed a list of 18 topics. These topics were then presented to 20 soccer referee experts to examine content validity. In terms of grade levels, these individuals were mostly emeritus (retired) referees, ranging from Grade 13, 12, 11, and at least one was still active as a Grade 2. Each expert was given a copy of the survey and asked to rank the validity of each topic from 1 (not valid) to 5 (very valid) in respect to education topics for referees, and to provide feedback on suggested changes. Minor changes were made to the demographic questions and syntax of certain topics, but the list of 18 was retained and the survey was confirmed as valid. This method of using expert reviewers that are knowledgeable on topics has been cited as a way to establish face validity (Worthington \& Whittaker, 2006).

The final questionnaire included 18 items and began with a stem question of "please rate how helpful each of the topics would be for you as a referee" and a 5-point Likert-type scale of 1 (not at all helpful) to 5 (extremely helpful), was used to score the items. Final items can be found in Table 1. The survey showed a Cronbach's Alpha of .88, which satis-

Table 1

Referees Preferences for Continuing Education Topics

\begin{tabular}{lcc}
\hline Topic & $\boldsymbol{M}$ & $\boldsymbol{S D}$ \\
\hline Player Management & 4.31 & .82 \\
Using Personality to Manage Games & 4.08 & .96 \\
Decision Making Process & 4.04 & .94 \\
Referee Teamwork/Communication & 3.89 & .98 \\
Misconduct Recognition & 3.87 & .97 \\
& & \\
Foul Recognition & 3.75 & 1.08 \\
Sport Psychology & 3.70 & 1.11 \\
Tactical Fouls & 3.70 & .99 \\
Managing the Technical Area & 3.69 & 1.01 \\
& & \\
Team Tactics & 3.64 & 1.09 \\
Pre-Game Preparation & 3.63 & 1.08 \\
Fitness & 3.59 & 1.24 \\
Offside & 3.58 & 1.14 \\
Effective Fourth Officiating & 3.57 & 1.15 \\
& & \\
Dissent & 3.45 & 1.05 \\
Gender Differences & 3.35 & 1.10 \\
Administrative Duties & 3.11 & 1.14 \\
Handling & 3.11 & 1.08
\end{tabular}


fies the recommended reliability of .70 level or higher (Nunnally, 1978). In the current study, the reliability for the SRCES was a Cronbach's Alpha of .88.

Demographic Questionnaire. A questionnaire was created that requested demographic information such as: age, gender, height, weight, referee grade level, years of experience, other sports officiated, registered state, highest level officiated, highest level of education, and number of days exercised per week.

\section{Results}

Results of this survey found that of the 18 educational topics presented ref- erees most wanted to learn more about player management $(M=4.31, S D=$ .82), using personality to manage games $(M=4.07, S D=.96)$, and the decision making process $(M=4.04, S D=.94)$. Referees were least interested in learning about gender differences $(M=3.35, S D$ $=1.10)$, administrative duties $(M=3.11$, $S D=1.14)$, and handling $(M=3.11, S D$ $=1.07)$. All results can be found in Table 1. This pattern did not differ based on gender (see Table 2).

A MANOVA was conducted to determine if there were differences for each educational topic based on experience level. Participants were separated into

Table 2

Referees Preferences for Continuing Education Topics by Gender

\begin{tabular}{|c|c|c|c|c|}
\hline \multirow[b]{2}{*}{ Topic } & \multicolumn{2}{|c|}{ Male } & \multicolumn{2}{|c|}{ Female } \\
\hline & $M$ & $S D$ & $M$ & $S D$ \\
\hline Player Management & 4.32 & .82 & 4.27 & .83 \\
\hline $\begin{array}{l}\text { Using Personality to } \\
\text { Manage Games }\end{array}$ & 4.08 & .96 & 4.04 & .92 \\
\hline Decision Making Process & 4.03 & .94 & 4.08 & .95 \\
\hline $\begin{array}{l}\text { Referee Teamwork/ } \\
\text { Communication }\end{array}$ & 3.91 & .96 & 3.69 & 1.05 \\
\hline Misconduct Recognition & 3.84 & .98 & 4.03 & .90 \\
\hline Foul Recognition & 3.74 & 1.10 & 3.85 & .96 \\
\hline Sport Psychology & 3.69 & 1.11 & 3.70 & 1.11 \\
\hline Tactical Fouls & 3.67 & 1.02 & 3.87 & .84 \\
\hline Managing the Technical Area & 3.69 & 1.00 & 3.65 & 1.03 \\
\hline Team Tactics & 3.69 & 1.07 & 3.38 & 1.16 \\
\hline Pre Game Preparation & 3.63 & 1.07 & 3.59 & 1.15 \\
\hline Fitness & 3.60 & 1.24 & 3.50 & 1.22 \\
\hline Offside & 3.58 & 1.16 & 3.57 & 1.12 \\
\hline Effective Fourth Officiating & 3.58 & 1.16 & 3.52 & 1.11 \\
\hline Dissent & 3.43 & 1.07 & 3.53 & .95 \\
\hline Gender Differences & 3.35 & 1.10 & 3.35 & 1.11 \\
\hline Administrative Duties & 3.15 & 1.15 & 2.92 & 1.02 \\
\hline Handling & 3.11 & 1.09 & 3.11 & 1.00 \\
\hline
\end{tabular}


one of three categories; less experienced (0-5 years), somewhat experienced (610 years), and more experienced $(>10$ years). These cut-offs were established by splitting the data in thirds. There was a significant multivariate effect, Wilks' Lambda $=.94, F(36,1872)=1.66, p$ $=.009$. Follow up ANOVAs indicated there were differences for player management, $(F(2,953)=6.00, p=.003)$, and administrative duties $(F(2,953)=$ $3.23, p=.04)$. Based on Tukey's post hoc, those less experienced $(M=4.18, S D=$ $.88)$ wanted less player management than those with more experience $(M=4.41$, $S D=.76)$ or somewhat experience $(M=$ 4.32, $S D=.81)$. Additionally, those less experienced $(M=3.25, S D=1.15)$ wanted more administrative duties than those with more experience $(M=3.01, S D=$ 1.17). All means and standard deviations can be found in Table 3 .

\section{Discussion}

The aim of this study was to explore the continuing education preferences of referees registered with the United States Soccer Federation Referee Program. It was found that: (i) referees across all experience levels and genders agree that player management, using personality to manage games, and the decision-making process were top preference topics and (ii) those less experienced specifically preferred educational topics of player management and administrative duties compared to those more experienced.

All referees agreed that player management would be the most helpful topic in regard to continuing education. Cunningham, Simmons, and Mascarenhas (2018) noted that in order to be successful, referees must learn how to encourage perceptions of fairness and convince athletes to act in cooperation and compliance when not receiving their desired decision. The ability to do so is in large part due to the ability to communicate with athletes (Fruchart \& Carton, 2012; Mellick, Bull, Laugharne, \& Fleming, 2005; Simmons, 2011) yet the difficulty of doing so would be compounded by players preferring referees when they are unobtrusive and do not interrupt the flow of the game (Mascarenhas, O'Hare, Plessner, \& Button, 2006). There are many additional aspects that must be addressed with player management. Nikbakhsh, Alam, and Monazami (2013) highlighted the need for heightened emotional intelligence in order to best address players' temperaments and personalities. Cunningham, Simmons, and Mascarenhas (2018) interviewed officials following the viewing of sport situations. They found three main themes regarding how referees interact with athletes: (a) anticipating players' reactions and modifying presentation of self; (b) asserting and preserving officials' face, and (c) giving and restoring players' face. Respondents provided many examples of how they manage athletes including managing body language, verbal tone, and showing empathy. Perhaps most interesting, was that referees reported tailoring their response to the situation. These are all complex concepts that would require both time and practice to master, which may also explain why using personality to manage games was ranked second most helpful among all participants.

Administrative duties and handling were ranked as the least helpful topics across all levels. In regard to administrative duties this may be due to a lack of 
Table 3

Referees Preferences for Continuing Education Topics by Experience Level

\begin{tabular}{|c|c|c|c|c|c|c|}
\hline \multirow[b]{2}{*}{ Topic } & \multicolumn{2}{|c|}{$\begin{array}{c}\text { Less } \\
\text { Experienced }\end{array}$} & \multicolumn{2}{|c|}{$\begin{array}{l}\text { Somewhat } \\
\text { Experienced }\end{array}$} & \multicolumn{2}{|c|}{$\begin{array}{c}\text { More } \\
\text { Experienced }\end{array}$} \\
\hline & $M$ & $S D$ & $M$ & $S D$ & $M$ & $S D$ \\
\hline Player Management & 4.18 & .89 & 4.30 & .89 & 4.39 & .79 \\
\hline $\begin{array}{l}\text { Using Personality to } \\
\text { Manage Games }\end{array}$ & 3.97 & 1.02 & 4.08 & 1.00 & 4.05 & 1.06 \\
\hline Decision Making Process & 4.04 & .96 & 3.96 & 1.01 & 4.07 & .97 \\
\hline $\begin{array}{l}\text { Referee Teamwork/ } \\
\text { Communication }\end{array}$ & 3.88 & 1.02 & 3.83 & 1.07 & 3.83 & 1.05 \\
\hline Misconduct Recognition & 3.96 & 1.01 & 3.81 & .99 & 3.83 & .99 \\
\hline Foul Recognition & 3.85 & 1.05 & 3.67 & 1.12 & 3.74 & 1.08 \\
\hline Sport Psychology & 3.66 & 1.11 & 3.71 & 1.11 & 3.65 & 1.18 \\
\hline Tactical Fouls & 3.72 & 1.06 & 3.61 & 1.07 & 3.69 & 1.01 \\
\hline $\begin{array}{l}\text { Managing the Technical } \\
\text { Area }\end{array}$ & 3.67 & 1.00 & 3.70 & 1.04 & 3.66 & 1.01 \\
\hline Team Tactics & 3.54 & 1.13 & 3.60 & 1.14 & 3.75 & 1.06 \\
\hline Pre Game Preparation & 3.71 & 1.13 & 3.59 & 1.14 & 3.50 & 1.12 \\
\hline Fitness & 3.53 & 1.34 & 3.53 & 1.28 & 3.60 & 1.22 \\
\hline Offside & 3.58 & 1.15 & 3.39 & 1.07 & 3.62 & 1.17 \\
\hline Effective Fourth Officiating & 3.58 & 1.23 & 3.61 & 1.15 & 3.48 & 1.13 \\
\hline Dissent & 3.43 & 1.12 & 3.39 & 1.07 & 3.46 & 1.09 \\
\hline Gender Differences & 3.42 & 1.19 & 3.32 & 1.12 & 3.29 & 1.05 \\
\hline Administrative Duties & 3.24 & 1.17 & 3.08 & 1.15 & 3.00 & 1.13 \\
\hline Handling & 3.21 & 1.13 & 3.06 & 1.07 & 3.04 & 1.10 \\
\hline
\end{tabular}

exuberance by referees to fill out postmatch reports. Handling may be considered one of the less serious offenses in a soccer match, which could provide reason for referees to rank this topic so low.

\section{Experience Level}

Previous research has suggested that experience must be considered when studying referees (Goldsmith \& Williams, 1992). MacMahon, Helsen, Starkes, and Weston (2007), studied Belgium elite referees on their decision-making ability and found that with experience, came improved decision making ability; as referees developed, they engaged in greater, and different types of training, consistent with Anshel (1995) who in measuring 56 Australian basketball referees, noted that with experience, came improved performance. In a study in Belgium, 27 top-standard referees and assistant referees (that included 16 approved at the FIFA level), Catteeuw, Helsen, Gilis, and Wagemans (2009) found that the predictive variables for performance included 
referees' years of officiating experience, accumulated practice hours, and practice hours per week. While these studies support the notion that with experience comes more opportunities for training, it is still unknown as to whether it is the quality, or quantity, of training that determines good referee development. Based on the results of the current study, administrative duties were something novice referees wanted more of compared to experienced referees. Perhaps, since they are at the beginning stage of their career, they feel the need for more assistance with the basics which would include administrative paperwork.

However, it is important to note that while differences did exist, all referees noted the importance of managing players' personalities; for example, referees noted that having greater familiarity with athletes helps to improve the interaction by understanding boundaries. In these instances, referees might experiment with different ranges of emotions including humor or sarcasm (Cunningham, Simmons, \& Mascarenhas, 2018). Due to the complexity of this topic, it makes sense that all referees agreed on its importance.

\section{Limitations}

We should be careful generalizing findings to the current USSF grade system as it continues to shift and undergo changes. While a major strength of this study was the large data set, it is important to recognize that 52 of the 55 state associations responded, region 1 is under represented due to an issue with scheduling and Region 4, is heavily represented in this study (44.9\% of participants). As a result, results may show a bias toward that region.
It is also important to note that this is an exploratory study and additional information should be gathered from referees regarding their continuing education preferences. As well, it would be helpful to survey referees from lower levels, as well as those referees lost to attrition, to better understand the needs of all referees.

\section{Conclusion}

This information provides a base of knowledge for future organizations, instructors, researchers, and referees and has the potential to improve the current referee education curriculum. Based on the importance of player management as indicated by participants, and the relative absence of the topic in the current U.S. Soccer Referee Program presentations, it seems an important step would be to find ways to integrate such information into the current curriculum. However, the idea of player management is abstract, and teaching such an abstract idea to a wide variety of referees leaves a wide margin of error. Additional research will be needed to measure the efficacy of the trainings as well as that of the referees.

Much research remains in this area, but these findings provide a foundation upon which to build. Improving education for soccer referees will not only improve referee's performance and experience, but will also likely have a trickle-down effect on participants and coaches.

\section{References}

Anshel, M. (1995). Development of a rating scale for determining competence in basketball referees: Implica- 
tions for sport psychology. The Sport Psychologist, 9(1), 4-28.

Cote, J., Young, B., North, J., \& Duffy, P. (2007). Towards a definition of excellence in sport coaching. International Journal of Coaching Science, 1(1), 3-17.

Catteeuw, P., Helsen, W., Gilis, B., \& Wagemans, J. (2009). Decision-making skills, role specificity, and deliberate practice in association football refereeing. Journal of Sport Sciences, 11, 1125-1136.

Cunningham, I., Simmons, P., \& Mascarenhas, D. (2018). Sport officials' strategies for managing interactions with players: Face-work on the frontstage. Psychology of Sport and Exercise, 39, 154-162.

Day, D.J. (2008). From Barclay to Brickett: Coaching practices and coaching lives in nineteenth and early twentieth century England. Unpublished manuscript, De Montfort University, Leicester, UK.

Dorsch, K. D., \& Paskevich, D. M. (2007). Stressful experiences among six certification levels of ice hockey officials. Psychology of Sport and Exercise, 8, 585-593.

Dvorak, J, Graf-Baumann, T., Peterson, L. \& Junge, A. (2016). Editorial. The American Journal of Sports Medicine, 28, 1-2.

Fruchart, E. \& Carton, A. (2012). How do amateur soccer referees destabilize a match? Psicológica, 33, 435-449.

Goldsmith, P. A., \& Williams, J. M. (1992). Perceived stressors for football and volleyball officials from three rating levels. Journal of Sport Behavior, 15, 106-118.

Gray, C. E., \& Wilson, P. M. (2008). The relationship between organizational commitment, perceived relatedness, and intentions to continue in Canadian track and field officials. Journal of Sport Behavior, 31, 44-63.

Jordan, P., Upright, P., Forsythe, S. (2019). Rural Kentucky sport officials' perspectives on recruitment, training, and retention, KAHPERD, 55, 59-71.

Kellett, P. Shilbury, D. (2007). Umpire Participation: Is abuse really the Issue? Sport Management Review, 10, 209-229.

Kellett, P. \& Warner, S. (2011). Creating communities that lead to retention: The social worlds and communities of umpires, European Sport Management Quarterly, 11, 471-494.

Leedham, M. (2005). The coaching scorecard: A holistic approach to evaluating the benefits of business coaching. International Journal of Evidence Based Coaching and Mentoring, 3, 30-44.

MacMahon, C., Helsen, W., Starkes, J., \& Weston, M. (2007). Decision-making skills and deliberate practice in elite association football referees. Journal of Sports Sciences, 25, 65-78.

Mascarenhas, D., O'Hare, D., Plessner, H., \& Button, C. (2006). The psychological and performance demands of association football refereeing. International Journal of Sport Psychology, 37, 99-120.

Mellick, M., Bull, P., Laugharne, E., \& Fleming, S. (2005). Identifying best practice for referee communication in association and rugby union football: A microanalytic approach. Football studies, 8, 42-57.

Nikbakhsh, R., Alam, S., \& Monazami, M. (2013). The relationship between emotional intelligence, communica- 
tion skills and stress among Iranian Premier League referees. Annals of Biological Research, 4, 196-203.

Nordstrom, H., Warner, S., \& Barnes, C. (2016). Behind the stripes: female football officials' experiences, International Journal of Sport Management and Marketing, 16, 259-279, Retrieved from http://hdl.handle. net $/ 10342 / 5824$

Nunnally, J.C. (1978). Psychometric theory ( $2^{\text {nd }}$ ed.). New York: McGraw-Hill.

Palacios-Huerta, I. (2004). Structural changes during a century of the world's most popular sport. Statistical Methods \& Applications, 13, 241-258.

Philippe, F. L., Vallerand, R. J., Andrianarisoa, J., \& Brunel, P. (2009). Passion in referees: Examining their affective and cognitive experiences in sport situations. Journal of Sport \& Exercise Psychology, 31, 77-96.

Ridinger, L.L., Warner, S., Tingle, J.K., \& Kim, K.R. (2017). Why referees stay in the game. Global Sports Business Journal, 5, 22-37.

Simmons, P. (2011). Competent, dependable, and respectful: Football refereeing as a model for communicating fairness. Ethical Space: The International Journal of Communication Ethics, 8, 3342.

Theisen (2017, June 27) There's a nationwise shortage of youth sport referees, and it could get worse (Deadspin), Retrieved from https:/ / deadspin. $\mathrm{com} /$ theres-a-nationwide-shortageof-youth-sports-referees-1796469536

Ussoccer.com (2017). Retrieved February 11, 2017, from http://www.ussoccer. $\mathrm{com} /$ referees
Warner, S., Tingle, J.K., \& Kellett, P. (2013). Officiating attrition: The experiences of former referees via a sport development lens. Journal of Sport Management, 27, 316-328

Wiersma, L.D., \& Sherman, C.P. (2005) Volunteer youth sport coaches' perspectives of coaching education/ certification and parental codes of conduct. Research Quarterly for Exercise and Sport, 76, 324-338

Wolfson, S., \& Neave, N. (2007). Coping under pressure: Cognitive strategies for maintaining confidence among soccer referees. Journal of Sport Behavior, 30, 232-247.

Worthington, R.L., \& Whittaker, T.A. (2006). Scale development research: A content analysis and recommendations for best practices, The Counseling Psychologist, 34, 806-838.

Zarrabi-Kashani, M. (2013). Stressors and coping strategies of referees in the United States Soccer Federation leagues. Retrieved from ProQuest Digital Dissertations, 3574648. 